Abstract M12 Table 1 TRPV1 single nucleotide polymorphism, cough reflex sensitivity and cough frequency in chronic cough

\begin{tabular}{|c|c|c|c|c|c|c|c|}
\hline TRPV1 SNP & $\mathrm{n}$ & C5 ( $\mu \mathrm{M} / \mathrm{L})$ & $\begin{array}{l}\text { reg }^{n} \text { coeff. } \\
(95 \% \mathrm{Cl})\end{array}$ & $p$ & CF24 & 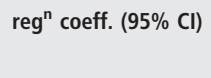 & $P$ \\
\hline rs161365 & 29 & $10.4(5.0-19.1)$ & -0.38 & 0.277 & $499(260-840)$ & -0.24 & 0.263 \\
\hline $\mathrm{cC}$ & 18 & $6.9(2.5-12.0)$ & $(-1.07$ to 0.31$)$ & & $458(111-636)$ & $(-0.68$ to 0.19$)$ & \\
\hline ст & 7 & $3.9(1.4-16.6)$ & & & $251(147-362)$ & & \\
\hline \multicolumn{8}{|l|}{ TT } \\
\hline rs17706630 & 37 & $7.8(4.9-15.6)$ & -0.34 & 0.487 & 436 (197-636) & 0.02 & 0.943 \\
\hline GG & 16 & $5.7(1.3-15.6)$ & $(-1.31$ to 0.63$)$ & & $362(120-976)$ & $(-0.59$ to 0.63$)$ & \\
\hline GA & 1 & 15.6 (n/a) & & & $154(n / a)$ & & \\
\hline \multicolumn{8}{|l|}{ AA } \\
\hline rs2277675 & 26 & $9.41(5.3-15.6)$ & 0.10 & 0.795 & $499(205-635)$ & -0.25 & 0.321 \\
\hline тт & 25 & $5.9(1.9-13.8)$ & $(-0.68$ to 0.89$)$ & & $362(154-1187)$ & $(-0.74$ to 0.25$)$ & \\
\hline TC & 3 & $22.1(3.9-49.6)$ & & & $104(42-285)$ & & \\
\hline \multicolumn{8}{|l|}{ CC } \\
\hline rs222741 & 28 & $7.8(3.9-15.6)$ & 0.38 & 0.274 & $338(111-636)$ & -0.14 & 0.534 \\
\hline AA & 18 & $5.4(2.5-23.0)$ & ( -0.31 to 1.08$)$ & & $425(292-738)$ & ( -0.31 to 0.59$)$ & \\
\hline AG & 7 & $12.0(7.8-16.6)$ & & & $567(212-611)$ & & \\
\hline \multicolumn{8}{|l|}{ GG } \\
\hline rs150854 & 19 & $11.0(5.5-16.6)$ & -0.29 & 0.525 & $458(147-611)$ & 0.32 & 0.237 \\
\hline тT & 28 & $6.1(3.4-17.1)$ & $(-1.18$ to 0.61$)$ & & $399(166-1081)$ & $(-0.22$ to 0.85$)$ & \\
\hline TG & 4 & $9.8(6.0-11.0)$ & & & $448(241-949)$ & & \\
\hline \multicolumn{8}{|l|}{ GG } \\
\hline rs224498 & 26 & $9.8(5.1-19.7)$ & -0.47 & 0.198 & $410(209-636)$ & 0.10 & 0.684 \\
\hline тт & 22 & $7.8(3.4-15.6)$ & ( -1.19 to 0.25$)$ & & $380(120-634)$ & $(-0.38$ to 0.57$)$ & \\
\hline TG & 6 & $6.7(0.5-11.0)$ & & & 695 (441-1985) & & \\
\hline
\end{tabular}

SNP - single nucleotide polymorphism, C5 - minimum capsaicin concentration required to produce 5 coughs, CF24 - 24-hour cough frequency. Values of C5 and CF24 are median (IQR). Regression coefficients are per minor allele effects from linear regression analyses with associated $p-$ values.

\section{M13 THE USE OF ONLINE HEALTH FORUMS BY CHRONIC COUGH SUFFERERS}

A Sinha, AM Wilson, T Porter. University of East Anglia, Norwich, UK

\subsection{6/thoraxjnl-2016-209333.455}

Introduction Chronic cough represents a significant health problem, affecting $10-20 \%$ of the population, for which effective medical support is often unavailable. ${ }^{1}$ In such circumstances, and having exhausted medical options, patients may turn to online health forums to exchange support and seek information. ${ }^{2,3} \mathrm{We}$ aimed to determine how patients use health forums and in turn, how medical professionals might utilise them in clinical practice.

Methods Three prominent open health forums were searched for threads related to cough, and screened against inclusion criteria adapted from the BTS guidance on cough ${ }^{1}$. Included threads were transcribed verbatim into QSR NVIVO, and subjected to qualitative thematic analysis. Findings were validated through the use of multiple reviewers.

Results 96 threads were reviewed, with contributions from 223 forum users. Three predominant themes emerged: the impact of chronic cough, treatment suggestions, and supportive posts. Regarding the impact of chronic cough, users highlighted the physical and psychological sequelae from prolonged chough, and the limitations imposed upon daily activities. Users suggested both prescribed treatments and alternative remedies, with many offering potential diagnoses to query with medical professionals. Supportive posts involved various strategies designed to show sympathy and empathy with others.
Conclusions Chronic cough patients use health forums to exchange information, advice and support. Health forums are a potential tool for clinicians wishing to access this population to provide medical care and promote patient education. We propose further research into these opportunities.

\section{REFERENCES}

1 Morice AH, McGarvey L, Pavord I. Recommendations for the management of cough in adults. Thorax 2006;61(suppl 1):i1-i24.

2 Nelson S, Hwang KO, Bernstam EV. Comparing clinician knowledge and online information regarding Alli (Orlistat). Int J Med Inform 2009;78(11):772-7.

3 Poole R, Smith D, Simpson S. How patients contribute to an online psychoeducation forum for bipolar disorder: A virtual participant observation study. JMIR Mental Health 2015;2(3):e21.

\section{M14 A MULTI-SITE ONLINE CROSS-SECTIONAL SURVEY ASSESSING INFLUENZA VACCINATION UPTAKE AMONG LONDON MEDICAL STUDENTS AND MODIFIABLE FACTORS INFLUENCING THIS}

GA Pankin, NE Jackson, IS Patel, AS Patel. King's College London, London, UK

\subsection{6/thoraxjnl-2016-209333.456}

Introduction and objectives Around 1 in 5 healthcare workers (HCWs) may become infected during the influenza (flu) season and between $28-59 \%$ will have subclinical illness which they could pass on to those more vulnerable. As a result, annual vaccination against flu is recommended for all UK National Health Service staff. However, during the 2015/16 season only 55\% of HCWs with direct clinical roles were vaccinated, with lower than 


\section{Abstract M14 Table}

\begin{tabular}{|c|c|}
\hline Variables & Number of students* \\
\hline Vaccinated & $132(44 \%)$ \\
\hline Not vaccinated & $170(56 \%)$ \\
\hline \multicolumn{2}{|l|}{ Clinical years } \\
\hline MBBS3 & $123(41 \%)$ \\
\hline MBBS4 & $88(29 \%)$ \\
\hline MBBS5 & $91(30 \%)$ \\
\hline \multicolumn{2}{|l|}{ Positive vaccine uptake across clinical years } \\
\hline MBBS3 & $51(41 \%)$ \\
\hline MBBS4 & $32(36 \%)$ \\
\hline MBBS5 & $49(54 \%)$ \\
\hline \multicolumn{2}{|l|}{ Teaching hospital } \\
\hline King's College Hospital & $121(40 \%)$ \\
\hline Guy's and St Thomas' Hospitals & $116(38 \%)$ \\
\hline University Hospital Lewisham & $54(18 \%)$ \\
\hline Not Applicable & $11(4 \%)$ \\
\hline \multicolumn{2}{|l|}{ Positive vaccine uptake across teaching hospitals } \\
\hline King's College Hospital & $44(36 \%)$ \\
\hline Guy's and St Thomas' Hospitals & $60(52 \%)$ \\
\hline University Hospital Lewisham & $22(41 \%)$ \\
\hline Not Applicable & $6(55 \%)$ \\
\hline \multicolumn{2}{|l|}{ Hours of patient contact per week } \\
\hline 1 to 5 & $21(7 \%)$ \\
\hline 6 to 10 & $71(23 \%)$ \\
\hline 11 to 15 & $79(26 \%)$ \\
\hline 16 to 20 & $59(20 \%)$ \\
\hline Over 20 & $72(24 \%)$ \\
\hline \multicolumn{2}{|l|}{ Positive vaccine uptake across hours of patient contact } \\
\hline 1 to 5 & $7(33 \%)$ \\
\hline 6 to 10 & $25(35 \%)$ \\
\hline 11 to 15 & $35(44 \%)$ \\
\hline 16 to 20 & $24(41 \%)$ \\
\hline Over 20 & $41(57 \%)$ \\
\hline \multicolumn{2}{|c|}{ Was the vaccine offered to those who were not vaccinated? } \\
\hline Yes & $62(36 \%)$ \\
\hline No & $108(64 \%)$ \\
\hline \multicolumn{2}{|l|}{ Did students receive information about the vaccine? } \\
\hline Yes & $151(50 \%)$ \\
\hline No & $151(50 \%)$ \\
\hline \multicolumn{2}{|l|}{ Who provided the information? } \\
\hline University & $7(5 \%)$ \\
\hline Hospital Trust & $111(73 \%)$ \\
\hline General Practitioner & $13(9 \%)$ \\
\hline Other & $20(13 \%)$ \\
\hline Provided with information and vaccinated & $102(68 \%)$ \\
\hline Not provided with information and vaccinated & $30(20 \%)$ \\
\hline \multicolumn{2}{|l|}{ Did students think they should get vaccinated? } \\
\hline Yes & $247(82 \%)$ \\
\hline No & $55(18 \%)$ \\
\hline \multicolumn{2}{|l|}{ Of those who thought they should get vaccinated } \\
\hline Were actually vaccinated & $121(51 \%)$ \\
\hline Were not vaccinated and not offered the vaccine & $79(73 \%)$ \\
\hline Were not vaccinated and not provided with information & $84(70 \%)$ \\
\hline \multicolumn{2}{|l|}{ Did students know how to access the vaccine? } \\
\hline Yes & $217(72 \%)$ \\
\hline No & $85(28 \%)$ \\
\hline
\end{tabular}

*The survey was disseminated to 1037 students. 302 students completed the survey. average rates seen in London. Like any HCW, medical students should be actively encouraged to get vaccinated. Our aim was to assess levels of flu vaccine uptake among London medical students and investigate the negative influences affecting uptake that could be addressed at an institutional level.

Methods A cross-sectional online survey, developed by a focus group of respiratory consultants and medical students, was disseminated to London medical students at King's College Hospital, Guy's and St Thomas' Hospitals and University Hospital Lewisham. Data was collected and analysed using SurveyMonkey Inc. Results 302 medical students completed the survey (Table 1). There was a good representation of students across different sites and clinical years. Overall, $44 \%$ students reported receiving the flu vaccine. Uptake varied between teaching sites and clinical years. $82 \%$ of students felt they should get vaccinated with $51 \%$ of those doing so.

$64 \%$ of those who were not vaccinated said they were not offered it, of whom $73 \%$ felt vaccination was appropriate. 50\% of all students said they were not provided with any information about the vaccine. $68 \%$ of those who were provided with information were vaccinated whereas $20 \%$ of those who were not provided with information were vaccinated.

Conclusions Vaccination rates among London medical students are lower than for most HCWs. There appears to be a discrepancy between willingess to get vaccinated and actual uptake rates. This may be due to a lack of information and encouragement rather than a lack of access, as $72 \%$ of all students were aware of how to access the vaccine. Teaching hospitals and the University should address this by introducing flu vaccination awareness into the curriculum and consider adding it to mandated occupation health assessments.

\section{M15 EVALUATION OF A NOVEL INTERVENTION FOR PATIENTS WITH BRONCHIECTASIS: THE BRONCHIECTASIS INFORMATION AND EDUCATION FEASIBILITY (BRIEF) STUDY}

${ }^{1}$ KLM Hester, ${ }^{1} \mathrm{~J}$ Newton, ${ }^{1} \mathrm{~T}$ Rapley, ${ }^{2} \mathrm{~A}$ De Soyza. 'Newcastle University, Newcastle upon Tyne, UK; ${ }^{2}$ Adult Bronchiectasis Service, Newcastle upon Tyne Hospitals NHS Foundation Trust, Newcastle upon Tyne, UK

\subsection{6/thoraxjnl-2016-209333.457}

Introduction There is currently limited information about bronchiectasis available to patients. We co-developed a novel patient and carer information resource, based on needs identified in previous work. ${ }^{1}$ The resource was evaluated in the BRIEF study with the following objectives:-

1. To establish the feasibility of carrying out a multi-centre randomised controlled trial (RCT) to determine effect on understanding, self-management and health outcomes.

2. To evaluate and refine the intervention.

Methods This was a feasibility study with a single-centre RCT design, comparing use of the resource to usual care in bronchiectasis. $^{2}$

Adults with bronchiectasis were recruited from respiratory clinics in the North of England. Those randomised to the intervention received the information resource (website www.bronchiectasis.me and booklet). Outcome measures (resource satisfaction, bronchiectasis knowledge, quality of life, unscheduled healthcare visits, exacerbation frequency, and lung function) 